\title{
TEORÍA Y PRÁCTICA DEL CINE "NACIONAL" EN LA GUERRA CIVIL ESPAÑOLA
}

\author{
ANDRÁS LÉNÁRT
}

Universidad de Szeged

\section{Theory and Practice of the "National" Cinema during the Spanish Civil War}

The insurgent army of the Spanish extreme right took advantage of the power of cinema, just like other Eumpean leaders did in the 20Th century. Between 1936 and 1939 (and during the whole regime as well) Spanish screens were spread with nationalist visual propaganda in order to shape the course of public opinion and to implant the ideology of the Falangist Movement in the citizens. General Franco, bis confidants and even bis relatives exerised tight control over film politics, giving preference to short films, documentaries and newsreels. In this essay we examine the theoretical and industrial background of the incipient francoist film politics during the Civil War and we bighlight some of the most important products of this effort, briefly touching upon a few relevant international matters, such as the anti-Franco movement of Hollywood or the German and Italian support.

En 1936 el Frente Popular ganó las elecciones en España. Esa unión política fue el fruto de la cooperación de las fracciones de la izquierda y extrema izquierda, pero también de algunas células moderadas del centro. La situación política y económica del pais exigía una intervención inmediata por parte de las fuerzas gobernantes, sobre todo concerniente a las cuestiones de la reforma agraria, la defensa de los intereses de los obreros y la legislación sobre la autonomía de las regiones. Los proyectos gubernamentales habrían conllevado cambios fundamentales en la estructura políticosocial del país y la ultraderecha (respaldada por un amplio abanico de grupúsculos de la derecha moderada) no se mostraba dispuesta a conformarse con las modificaciones. Falange Española de las Juntas de Ofensiva Nacional Sindicalista (después de 1937, tras la unificación de varios grupos, será FET y de las JONS, el partido único del franquismo) no permaneció inactiva ante las reformas inaceptables para su ideología anquilosada y apostó por una sublevación militar. La apoyaban los carlistas, un gran número de militares de alto rango y algunos sectores políticos que compartían las preocupaciones de Falange. El 17 de julio de 1936 se inició una serie de insurrecciones en varios puntos cruciales de España y el día siguiente la rebelión se generalizó, provocando un derramamiento de sangre espeluznante y una guerra fratricida de cuatro años. Los sublevados, que se autodefinían como "nacionales", se hicieron con el control del pais paso a paso, mientras que los defensores de la República procuraban salvaguardar su propio mando en los territorios bajo su vigilancia, aunque la 
colaboración entre estos grupos abundaba en encontronazos tambiẻn. Con el progreso de los combates el general Franciso Franco Bahamonde llegó a ser la figura decisiva de los nacionales, relegando a segundo plano a los otros dirigentes militares, y se proclamó jefe supremo.

La Guerra Civil Española supuso el primer verdadero enfrentamiento entre el fascismo y la democracia. Aunque oficialmente la mayoría de los países no se entrometió en la conflagración, mediante la intervención directa o indirecta de Italia, Alemania, la Unión Soviética y las Brigadas Internacionales la lucha cobró un carácter universal. La historiografia considera esta contienda como la antesala de la segunda guerra mundial, y lo hace con toda razón si profundizamos en la presencia de las tendencias políticas variopintas. Un cierto tipo de "laboratorio experimental", donde los países extranjeros tenían la posibilidad de sopesar las correlaciones de fuerzas, observar las tácticas militares, ensayar armamentos recién desarrollados y comenzar a sentar los fundamentos del espionaje moderno y de la propaganda bélica.

En los años turbulentos de la Guerra Civil se perfiló la imagen de dos Españas opuestas: las regiones controladas por la derecha y por la izquierda-centroizquierda se apartaron de manera bien perceptible, aunque los territorios de estas últimas se iban reduciendo por el avance del ejército del general Franco. Esa división en dos partes, naturalmente, ejerció influencia considerable en la industria fílmica.

Ante todo, hay que precisar el papel que el cine desempeña en tiempos de guerra y en la época posbélica en el funcionamiento cotidiano de los estados democráticos o totalitarios. La propaganda, la unificación del pueblo fiel a las doctrinas imperantes, la "nutrición" de su entusiasmo y el debilitamiento del crédito y de la firmeza del enemigo dio con un medio apropiado en esta representación móvil de la realidad. Lenin se percató pronto de que la película pudiera ser la creación artística más importante, idónea para corroborar su ideología. A lo largo de los años y décadas prácticamente todos los gobernantes notables (generalmente dictadores: Hitler, Stalin, Mussolini, Kim Jong-Il) del siglo 20 legaron a la misma conclusión y a esa línea se sumó Franco también. Incluso el mismísimo general, como cineasta aficionado, rodó cortometrajes mientras se combatía en las batallas".

Esa "lucha cinematográfica" tenía carácter diferente en los dos bandos. Por lo que atañe al género de las obras, el material rodado mostraba homogeneidad: las películas documentales y los noticiarios entraton en primer plano, en perjuicio de los largometrajes.

Tanto el bando nacional como el republicano emprendió una filmación propia, aunque con distinta calidad y cantidad. Una estadística sobre la filmografia de la Guerra Civil $^{2}$ indica que en el período de 1936-1939 los partidarios del gobierno legítimo rodaron 360 películas (largometrajes, cortos, documentales y noticiarios incluidos). Entretanto, el número de las piezas hechas por los sublevados alcanza solamente el 93.

\footnotetext{
1 Gabriel REBELLÓN DOMINGUEZ, Seis meses en Yebala, Madrid, 1925, 93.

2 Alfonso del AMO, Catálogo general del cine de la Guerra Civil, Madrid, Cátedra - Filmoteca Española, 1996, 31.
} 
No entramos en detalles en cuanto a la cinematografia de la zona republicana, porque es bastante ajeno al núcleo de interés del presente trabajo, sólo acentuamos lọ que es imprescindible desde el punto de vista de nuestro tema. El hecho más relevante: casi toda la infraestructura recién formulada de la cinematografia, los estudios, el personal técnico y los aparatos e instrumentos indispensables habían quedado en territorios bajo dominio republicano (el centro cinematográfico de la época era Barcelona). Los partidos y organizaciones que habían compuesto el Frente Popular antes de la guerra dieron rienda suelta a su producción cinematográfica individual, sobre todo a la realización de películas documentales y noticiarios. Por lo tanto, podemos hablar de producción gubernamental, marxistz, anarquista y sindical; cada grupo poseía un propio centro de propaganda. Los operadores tenían la obligación de entregar el material rodado a un comité designado por el partido u organización en cuestión y con su consentimiento las películas ya podian entrar en la corriente de distribución nacional e internacional ${ }^{3}$. Los largometrajes los importaban desde el extranjero, la filmación se concentró en la confección de documentales y noticiarios, indispensables para abastecer la propaganda bélica. Expropiaron los estudios, la maquinaria filmica y las salas de proyección. Debido a las incautaciones las antiguas productoras de propiedad privada no aportaron filmes de gran envergadura a la cinematografia republicana.

\section{El bando nacional y su representación cinematográfica}

La actividad filmica de los nacionales ofrece algunas peculiaridades. Para comenzar, hay que subrayar que la expropiación de productoras y cines aqui no tuvo una trascendencia tan grande como en el lado contrario. Al márgen de la cinematografia oficial de los sublevados seguian sus actividades algunas productoras privadas filofascistas en cooperación armónica con el aparato franquista; esas empresas podían producir, distribuir y exhibir sus materiales solamente con el visto bueno de los ejecutivos políticos. La más brillante fue Cifesa, productora de la dinastía Casanova, una familia conservadora católica. A lo largo de los años cuarenta Cifesa (según su lema, "La antorcha de los éxitos") se vanagloriaba de los largometrajes más pomposos y emblemáticos de la dictadura, sobre todo dentro del subgénero taquillero llamado "cine de cartón piedra".

La sublevación trajo consigo la unificación de las tropas y de las entidades promotoras bajo la denominación Movimiento Nacional. Dentro de este Movimiento, a pesar de la coparticipación incondicional, existían desacuerdos y pequeños temblores constantes entre las fracciones, pero la figura egregia de Franco aseguraba la unidad. Desde el punto de vista del credo imperante, la Falange tenía el papel decisivo durante la contienda. Los falangistas habían comenzado a formular las técnicas propagandísticas ya mucho antes de la guerra, y en ellas los cineclubes ocupaban un rango prestigioso. Es esos clubes proyectaban películas de la Alemania nazi y de la Italia fascista junto con largometrajes internacionales con un contenido aparentemente inofensivo.

3. Magi CRUSELLS, La Guerra Civil española: cine y propaganda, Barcelona, Editorial Ariel, 2000, 56-57. 
El teórico supremo de Falange y del Movimiento Nacional era Ramón Serrano Súñer, cuñado de Franco, más tarde ministro de interior y exterior, persona clave en cuanto al apaciguamiento de las diferentes agrupaciones dentro del Movimiento. Su tarea principal consistía en organizar y llevar a cabo la propaganda franquista dogmática.

Se formuló una estrategia para tratar a la masa de gente de manera uniformizada y esa tesis servía como cimiento para el planteamiento de las películas propagandísticas. En 1937 un autor anónimo publicó Estéticia de las muchedumbrest, un artículo que acota las pautas para el adiestramiento sistemático de la gente. Su punto de partida: a raíz de la primera guerra mundial, por influjo de la propaganda bolchevique, los pueblos de Europa malgastaron la capacidad del pensamiento claro, los partidos nacionales se quebrantaron y en la actualidad ya no son aptos para representar los intereses de la gente. La unión de las fuerzas y almas patrióticas engendra una nueva mentalidad y un nuevo estado, presidido por un caudillo firme, fuerte e intransigente. Este glorioso líder será el mesías de su pueblo, lo dirige hacia el camino apropiado.

Cada uno de los discursos y apariciones filmados de Franco tomó como base la teoría que la gente reivindica a un líder carismático y la captación de los acontecimientos heroicos, festivos y religiosos (reales o ficticios) aporta una nueva dósis de empuje al sujeto para que se someta a los imperativos de la Patria. El espectador ha de sentir que él mismo forma una parte imprescindible del Nuevo Estado, que ese imperio existe y funciona para satisfacer las exigencias del ciudadano, todo lo que ocurre y lo que se ve en las pantallas tiene por objetivo crear un cierto tipo de paraíso terrenal. Pero este plan alcanza su finalidad solamente si el público de estas películas toma conciencia de que el emisor ha dirigido la palabra a ellos no como a individuos, sino como a miembros de un colectivo. Este colectivo, la muchedumbre debe ser el súbdito obediente del régimen franquista, porque hacían hincapié en que el sistema impuesto por el Caudillo quiere lograr el bienestar y la salvación del Nuevo Estado español.

¿Cómo es el cine franquista? Como lo hemos mencionado más arriba, los largometrajes no tenían gran importancia para los combatientes: rodar uno habría requerido una inversión financiera insoportable en tiempos de guerra y la propaganda oculta en ello tampoco habría sido tan directo y eficaz como en el caso de los documentales y noticiarios. Los dirigentes preferian estos dos últimos géneros. Salvo algunas excepciones, estas películas no disponían de un autor, director u operador concreto, las rodaron bajo la égida del Departamento de Propaganda de FET y de las JONS o la de la Sección Cinematográfica.

Estas obras, todas hechas con intención propagandística, tienen varios rasgos comunes. Uno de estos es la relación especial entre la imagen y el comentario. El potencial de estas películas reside no exclusivamente en los fotogramas, pero en el componente verbal también. La fuerza visual de las imágenes que retratan el bombardeo de una ciudad o la llegada de las tropas nacionales proviene del hecho de que el film vincula íntimamente los acontecimentos a los espectadores, como si ellos

4 ANÓNIMO: "Estética de las muchedumbres", in: Vértice, 3, junio de 1937. 
mismos participaran en ellos. Destrucción total, ruinas y cadáveres por todas partes. No obstante, sin incorporar el componente verbal, muchas veces no sería evidente si estemos viendo una película propagandística franquista o un film antifranquista rodado por los republicanos. Pero el narrador nos hace palpable qué es lo que tenemos que comprender. Se pasó varias veces que los dos bandos adversos utilizaron exactamente las mismas tomas, pero las comentaron de manera distinta, así los fotogramas obtuvieron interpretaciones dispares. Aún más, con la ayuda del montaje recopilaron imágenes sobre acontecimientos que no tenían nada que ver entre sí, pero con este proceso creativo los sucesos yuxtapuestos, coronados con un comentario explícito, ganaron nuevo sentido. Las cámaras buscaban momentos y episodios de la guerra con los cuales podían contraponer la devastación, causada por el enemigo, a los éxitos del ejército patriótico triunfante. Naturalmente, empleaban la exageración lírica siempre, llena de hipérboles: los insurrectos arriesgan su vida voluntariamente, son conscientes de que posiblemente no volverán a encontrarse con su familia, pero el bien de la Patria se antepone a los sentimientos personales. Si ellos no se atreven a enfrentarse con el enemigo malvado, su amada España será arruinada por los "rojos, comunistas, bolcheviques y masónes endemoniados" (valiéndonos de la terminología franquista). Otro elemento permanente es la presencia del Caudillo. Aunque a lo largo de las películas se evoca el personaje de Franco constantemente (mediante alusiones en el comentario, fotos y retratos, etc.), en los últimos minutos de los filmes él se manifiesta personalmente también, generalmente a propósito de un discurso sólemne. Existía una norma bien expuesta: durante la guerra, la aparición del general debe ser la conclusión ceremonial de las películas nacionales ${ }^{5}$.

Uno de los temas recurrentes de esos cortometrajes y noticiarios es la bispanidad. Los españoles y latinoamericanos pertenecen a la misma raza, la raza hispana, un corchete invisible mantiene juntas la génesis de la cultura de la península Ibérica y la del florecimiento intelectual de Iberoamérica. Actualizando las tesis de Ramiro de Maeztu, Falange recalcó la unión de los pueblos hispanos. Acto seguido, la propaganda hecha para los ciudadanos españoles se completó con imágenes rodadas para los países latinoamericanos. Aparte de las noticias filmadas los sublevados no disponían de material filmico exportable, por eso de los noticiarios y cortometrajes españoles hicieron un remontaje, añadieron una narración ideal para los hispanoamericanos y enviaron esta versión puesta al día al nuevo continente. Los logros más notables de este procedimiento son Alma y nervio de España (1936) y España azul (1937), producciones de la Sección de Cinematografía de la Delegación Nacional de Prensa y Propaganda de FET y de las JONS 6 . Tanto las organizaciones franquistas oficiales como particulares filofranquistas viajaron regularmente a América Latina con el fin de dar cuenta de las

\footnotetext{
5 Archivo General de la Administración, Cultura (en adelante: AGAC), Alcalá de Henares, caja 21/00001. Despacho sin fecha y firma.

"Aunque algunas bases de dato indican erróneamente que Joaquín Martínez Arboyela fue el director de ambas películas, es evidente que se trata de una obra colectiva, por eso no le consideramos como el verdadero realizador.
} 
victorias del ejército nacional y de divulgar los valores del futuro Nuevo Estado. Estos "agentes" fueron acompañados por equipos de rodaje para documentar los mitínes y dejar constancia sobre el ambiente acogedor (y muchas veces manipulado) que esperaba a los oradores falangistas.

En los sucesivo destacamos algunas obras, todas hechas por los insurrectos durante la contienda, para demostrar el hilo ideológico que seguían estas películas.

Una de las joyas de la propaganda franquista es Frente de Vizcaya y 18 de julio (1937), producción de la misma delegación que había hecho los filmes anteriores. Esta película demuestra el anvance franquista en el norte y el desmoronamiento que los republicanos han dejado atrás. Por supuesto, todo desde un punto de vista fuertemente subjetivo e ideologizado. Desfilan ante nuestros ojos todos los rasgos característicos que están presentes en la mayoría de las películas de la ultraderecha, como, por ejemplo, usar atributos extremos y llenos de odio al calificar al enemigo como hordas moscovitas, separatistas rojos, etc. Según la propaganda de los sublevados cada uno de los españoles que apoyaba la República pertenecía a los colaboracionistas bolcheviques, y el comunismo, tal como las otras ideas izquierdistas, era el credo del Satán. Uno de los momentos más interesantes de esta cinta es la destrucción de Guernica cuyo destino llegó a ser el símbolo alarmante de los horrores de la Guerra Civil. Según el juicio de la historiografia oficial, aceptado hoy más o menos con unanimidad, la legión Cóndor alemana, con el amparo de algunos aviones italianos, bombardeó esa población vasca, causando la muerte de unas 250-300 personas. La propaganda falangista de la época intentaba hacer recaer la responsabilidad del ataque sobre los republicanos, sosteniendo que los rojos habían prendido fuego a las casas durante su retirada, mucho antes de la llegada de las tropas franquistas. Para justificar su afirmación, citaron como corroboración sus propias películas, como la de Frente de Vizcaya, defendiendo que según esas imágenes era evidente que se trataba de un incendio y no de un bombardeo. Es interesante observar que algunas veces los republicanos usaron los mismos fotogramas que los nacionales para comprobar su propia razón. O sea, otra vez, las mismas tomas, pero con dos explicaciones completamente divergentes. Esas coincidencias podían ocurrir fácilmente, porque los franquistas de vez en cuando se apoderaban de los materiales de los republicanos cuando los habían expulsado de sus zonas ${ }^{7}$. Sin embargo, hoy ya existen pruebas irrefutables para afirmar que la agresión fue cometida por los alemanes (el famoso cuadro de Pablo Picasso pintado para la Exposición de París nació como conmemoración también).

Actualmente ha resurgido el debate de Guernica, sobre todo en círculos científicos. Historiadores de cine y aficionados han examinado casi la totalidad de los rollos disponibles sobre la destrucción de Guernica con la asistencia de expertos de incendio y su conclusión es bastante sorprendente: según ellos, las pruebas filmicas parecen dar la razón al discurso franquista, hoy negado por casi todo el mundo. En el futuro cercano los

\footnotetext{
7 Véase la monografia detallada sobre el País Vasco en la cinematografia de la Guerra Civil: Santiago de PABLO, Tierra Sin Paz. Guerra Civil, cine y propaganda en el País Vasco, Madrid, Bibloteca Nueva, 2006.
} 
cinéfilos y los historiadores volverán a analizar las películas relevantes, aunque tienen en cuenta que es un problema peliagudo y que están caminando en la cuerda floja.

Se hizo un número no desdeñable de filmes sobre la llegada y el asentamiento de las tropas franquistas en lás zonas antes republicanas. Un rasgo común de ellos es que la entrada a la región es heroica, majestuosa. Depuran el territorio de los traidores a la patria y emprenden los primeros pasos para reconstruir las casas, iglesias y escuelas que han sido demolidas por los rojos. Conceden ayuda a la población deseperada y aceptan con modestia la oleada de agradecimientos que reciben de la gente. La iglesia es un elemerito" simbólico: el nacionalcatolicismo y el papel incuestionable de la Iglesia cátólica son los pilares primordiales de la cruzada de Franco. La mayoría del clero apoyaba a los sublevados casi incondicionalmente, así no fue sorprendente que los republicanos incendiaran iglesias y conventos. $O$ sea, cuando las peliculas franquistas hablan de republicanos anticlericales, no están lejos de la verdad, sus reproches tienen fundamentos.

Otra piedra angular de la propaganda visual franquista es Prisioneros de guerra (Manuel Augusto García Viñolas, 1938). Ya que los republicanos se quejaban de las condiciones inhumanas en los campos de prisioneros, los falangistas rodaron este cortometraje a título de refutaciọ́ñ. Según el "cuento" de la película el ejército trata a los presos con respeto y sacian todas sus necesidades. Asisten a los enfermos en hospitales higiénicos y emplean la terapía de trabajo: al prisionero de guerra español le hace muy feliz poder tomar parte en la reconstrucción de puentes y carreteras para la Nueva España. Pero no sólo eso: con la retórica nacional los franquistas logran convencer a muchos republicanos capturados de que su ideología nacionalcatólica es la única salvación para España, asi los izquierdistas aceptan la nueva doctrina voluntariamente. Este tipo de "țeatro filmado", ụna película de ficción, pero llamada documental por su realizador, tería la tarea de demostrar al pueblo y al extranjero que la vida en el país franquista es la mejor posible y. que el general Francisco Franco cuida a sus ciudadanos, independientemente de sus convicciones políticas e ideológicas. La propaganda cinematográfica cumplió con su deber, principalmente bajo la tutela de la Delegación del Estado para Prensa y Propaganda (DEPP).

\section{Marco legal e institucional}

- En la primera fase de la sublevación todavía no existían instituciones oficiales para gestionar los asuntos cinematográficos. Al márgen de la propaganda, el énfasis recaía en la censura.

La censura cinematográfica no es una invención española, ni siquiera dictatorial. La "Fábrica de Sueños". de Hollywood ya tenía sus normas desde los años 1930 en forma fijada. Este marco fue el Motion Picture Production Code, o en su denominación informal, Código Hays (por el censor supremo, Will Hays). Este código, respaldado por la Iglesia Católica, precisó en sus párrafos qué contenido se tachaba de moralmente aceptable o inadmisible. El contenido del código no fue determinado por el estado, sino por un cuerpo de clérigos y magnates católicos, pero ni siquiera los productores todopoderosos 
se atreveian a llevar la contraria a las propuestas, porque los líderes estatales y eclesiásticos (que respetaban las instrucciones como la Santa Escritura) tenían la posibilidad de exhortar al pueblo norteamericano a boicotear el film concreto o todos los productos del estudio.

Y'no olvidemos que en España ya se había creado la censura previa en la época del gobierno conservador de Antonio Maura que comprendía todas las ramas artísticas, pero con un rigor menos severo y con aspectos diversos.

En los territorios nacionales durante la Guerra Civil la censura era omnipotente y omnipresente. Tanto el material difundido por los republicanos como los largometrajes rodados antes de la contienda llegaron a ser el blanco de los censores y, desde luego, las obras extranjeras tampoco se quedaron intactas. Los cortes, el remontaje, el doblaje o la prohibición definitiva componían los instrumentos operativos.

La actividad censora era bastante caótica. A terior de un decreto de $1937^{8}$ se constituyeron dos juntas responsables de la censura, ubicadas en varios lugares de la península, pero al final ambas recibieron su centro permanente: la primera en Sevilla y la segunda en la sede del gobierno franquista, Burgos. Esta última era la Junta Superior de Censura, estrechamente ligada al gobierno y a veces en desacuerdo con el cuerpo de Sevilla. Además, la iglesia, la Asociación Católica Nacional de Propagandistas, la Confederación de Padres de la Familia y varias otras entidades podían ejercer censura sobre las películas que iban a proyectarse en territorio nacional. Sin un marco óficial con indicaciones expresas, esos grupos llegaron con frecuencia a conclusiones diferentes y de estos desencuentros surgió una retahíla de conflictos variopintos.

La tarea más importante de las instituciones cinematográficas, con arreglo al decreto que las había creado, constaba de la vigilancia de las cintas en tomo a las batallas y, además, las productoras y los particulares tenían la obligación de facilitar a la Sección de Cinematografia todos los materiales que rodaban durante la guerra ${ }^{9}$. Para dar un marco legislativo a sus disposiciones, el ministro del interior, Ramón Serrano Súñer añadió: "Debido a la influencia que el cinematógrafo tiene en la difusión del pensamiento y en la educación de las masas... el Estado vigile en todos lós órdenes en que haya riesgo de que se desvíe su misión"10, o sea, el gobierno quería controlar todo que habría podido servir como fuente de cualquier peligro.

A pesar de la confusión, revisando los informes censoriales podemos afirmar con certeza qué es lo que el aparato franquista no toleraba en las pantallas bajo ninguna circunstancia. Las escenas sobre huelgas y manifestaciones, alusiones a la clase obrera o la lucha de clases, la representación visual de la miseria y de la desocupación fueron entroncados con el comunismo y con la propaganda bolchevique, de ahí que los largoy cortometrajes, documentales y noticiarios de contenido semejante caían bajo

\footnotetext{
8 Boletín Oficial del Estado (en adelante: BOE), 27 de marzo de 1937.

$9 \mathrm{BOE}, 6$ de julio de 1938.

10 BOE, 2 de noviembre de 1938.
} 
proscripción absoluta ${ }^{11}$. Además, en defensa de la moral, náda de erotismó y sexualidad. Si una productora extranjera quería distribuir y exhibir su película en suelo eșpanool, ella tenía que adaptarse à esas directrices también.

Los productos de los Estados Unidos fueron afectados por una censura distinguida, ya que Hollywood habia exásperado a Franco con algunas actividades. La flor y la nata de los cineastas renombrados no se éscondía para amparar la España républicaná y llamaron la atención al mundo sobre la brutalidad de Franco'y al matiz ilegal de sus acciones violentäs. Organizaron recaudaciones, veladas benéficas y ruedas de prensa internacionales, fundaron varias asociaciones para apoyar el gobierno légitimo de España. Franco tildó de marxistas a todós los actores, directores y guionistas que se asociaron a estas manifestaciones y prohibió sin inmutarse que sus películas anteriores y actuales se exhibieran en pantallas españolas. Pusieron a esas listas negras incluso a aquellas personas que intervenían en películas prorrepublicanas. Así el público español no pudo contemplar durante años a Charlie Chaplin, Joan Crawford, Bette Davis, Bing Crosby, Henry Fonda, Douglas Fairbanks Jr, James Cagney, Humphrey Bogart, Lauren Bacall y Spencer Tracy, entre otros, ni las obras de Fritz Lang, John Ford y Lewis Milestone. Se impidió la mención de estos nombres en los periódicos, junto con los de Ernest Hemingway, Upton Sinclair, John Dos Passos, Thomas Mann, Dashiell Hammett, Theodore Dreiser y Albert Einstein, también "culpables" de ser antifranquistas ${ }^{12}$.

El desdén falangista contra esas estrellas estadounidenses queda patente en el artículo de un corresponsal español, publicado en un diario argentino: "España, que sabrá olvidar tantas cosas ... no sabrá perdonar ni olvidar, sin embargo, la perfidia de estas casas productoras de Hollywood, casi todas ellas judias, y de esos artistas que olvidaron su misión para ayudar desde una retaguardia tan lejana y tan frívola como la de Hollywood, a un Gobierno rojo que, gracias a estas ayudas, prolonga la agonía de los que en la zona que dominan esperan angustiados su liberación"13.

Dado que el Caudillo no podía estribar en los cimientos formulados de la infraestructura filmica, necesitaba auxilio extranjero. Mediante contratos generales o acuerdos cinematográficos Franco plasmó una cooperación singular con Hitler y Mussolini. Los dos países suministraron ayuda a España en forma de película virgen, aparatos técnicos y se efectuó el intercambio de obras de propaganda.

Alemania prestó atención extraordinaria a la supervivencia del cine español y de los cineastas: en 1938 el Führer comunicó personalmente al director Florián Rey y a la actriz Imperio Argentina que hasta que la situación política y las circunstancias laborales se normalizaran en España, los cineastas españoles más eximios, secuaces de Franco,

\footnotetext{
${ }^{11}$ Esta actitud queda reflejada por los decretos y normas promulgados el 4 de mayo de 1937 . AG.AC, caja $21 / 411$

12 Archivo del Ministerio de Asuntos Exteriores, Madrid, legajo R-1724/126. Despachos con fecha 18 de agosto de 1939 y 21 de agosto de 1939.

13 Citado por: Ramón SALA NOGUER y Rosa ÁLVAREZ BERCIANO, El cine en la zona nacional, Bilbao, Ediciones Mensajero, 2000, 46.
} 
podian beneficiarse de los estudios y el personal técnịco alemanes para que pudieran continuar su carrera de manera adecuada ${ }^{14}$.

Uno de los puntos culminantes de la colaboración hispano-alemana fue un documental del taller de Hispano-Film Produktion, España heroica (Joaquín Reig, 1938). Se trata de una sintesis de la propaganda fascista, empleando todos los elementos que caracterizaban las películas franquistas de. aquella época, pero de un nivel artístico mucho más elevado. Aunque el realizador utilizó segmentos de antiguos documentales y noticiarios, lo valoramos como un producto de alta calidad, impregnado con una ideología ultraderechista y anticomunista bastante intensa.

Desde 1938 Noticiario Español se convirtió en la fuente de información más notable en las pantallas. El principal propósito de este noticiario fue no sólo influir en el pueblo español, sino en los países extranjeros también para que abandonaran su posición de neutralidad y apadrinaran los objetivos de los sublevados. Aunque se trataba de un producto español, su trascendencia quedó eclipsada por los noticiarios alemanes y los del americano Fox-Movietone; sólo en 1942 naceria el NO-DO (Noticiarios y Documentales) oficial que se convertiría en uno de los símbolos supremos del franquismo.

El 1 de abril de 1939 Franco anuncia que "La guerra ha terminado". Esta fecha marca el primer día del sistema franquista en el cual el cine sigue ocupando un papel primordial entre los instrumentos de propaganda nacional. La política cinematográfica de Franco se asemeja en muchos rasgos a las de Alemania y de Italia, pero también a la de la Unión Soviética estalinista. Los cambios y rectificaciones en el sistema filmico, su cooperación con la política oficial y el reflejo de la ideología imperante en las pantallas ofrece una fuente valiosa de informaciones tanto para los historiadores de cine como para los investigadores de la historia y política de la España del siglo 20.

14 "La estrella que deslumbró a Hitler" en el diario El Mundo, 24/08/2003; 9. 